\title{
Assessment of the Sphericity of Submicrometer Particles Using a Single-particle Polar Nephelometer at an Urban Site in Japan
}

\author{
Maho Nakagawa ${ }^{1,2}$, Tomoki Nakayama ${ }^{1,3^{*}}$, Hiroshi Sasago ${ }^{1}$, Yuki Kuruma ${ }^{1,4}$, Hikari Yai ${ }^{5}$, \\ Shuhei Ogawa ${ }^{5}$, Yange Deng ${ }^{5,6}$, Michihiro Mochida ${ }^{1,5}$, Yutaka Matsumi ${ }^{1}$ \\ ${ }^{1}$ Institute for Space-Earth Environmental Research, Nagoya University, Chikusa-ku, Nagoya 464-8601, Japan \\ ${ }^{2}$ National Institute of Information and Communications Technology, Koganei, Tokyo 184-8795, Japan \\ ${ }^{3}$ Faculty of Environmental Science and Graduate School of Fisheries and Environmental Sciences, Nagasaki University, \\ Bunkyo-machi, Nagasaki 852-8521, Japan \\ ${ }^{4}$ National Institute of Advanced Industrial Science and Technology, Umezono, Tsukuba 305-8560, Japan \\ ${ }^{5}$ Graduate School of Environmental Studies, Nagoya University, Chikusa-ku, Nagoya 464-8601, Japan \\ ${ }^{6}$ National Institute for Environmental Studies, Tsukuba 305-8506, Japan
}

\begin{abstract}
The sphericity of particles must be considered when evaluating their effects on the climate and human health. Thus, to examine this property and its controlling factors, this study measured the scattering angular distributions of both thermodenuded and non-thermodenuded individual particles with a diameter of $500 \mathrm{~nm}$ in real time using a home-made polar nephelometer in Nagoya, Japan. Estimating the sphericities based on the depths of the local minima in the scattering angular distributions, we found the ambient aerosols to be external mixtures of at least two types of particles, one with relatively high and the other with relatively low sphericity. Although most of the particles exhibiting high sphericity were removed as they passed through the thermodenuder, approximately one-third of the fraction exhibiting low sphericity remained. During the daytime, the proportion of the low-sphericity particles decreased, whereas the average sphericity of the high-sphericity particles increased, which can be attributed to photochemical formation and/or aging processes. On days with extremely high relative humidity, the diurnal variation in the average sphericity displayed another peak during the early morning, which may have been due to the secondary formation of nitrate.
\end{abstract}

Keywords: Polar nephelometer; Scattering angular distribution; Single particle; Particle sphericity.

\section{INTRODUCTION}

Atmospheric aerosols play important roles in the earth's atmosphere, for example, through their effects on the climate system by scattering and absorbing sunlight and by acting as cloud condensation nuclei. However, partly due to the complexity of the physicochemical properties of these particles (Boucher et al., 2013), there are still large uncertainties associated with these effects. For instance, the angular distribution of light scattering, an effect of particles' various properties (size, refractive index, shape, and mixing state) (Boucher et al., 2013; Scarnato et al., 2013; China et al., 2015), is an important parameter in determining radiation balance in the atmosphere (Moosmüller et al., 2009). The particle shape (or particle sphericity) is an important factor

\footnotetext{
* Corresponding author.

Tel.: +81-95-819-2772

E-mail address: t-nakayama@nagasaki-u.ac.jp
}

controlling the motion of the particles and affecting human health because it can contribute to aerodynamic behavior and pulmonary deposition process of the particles (e.g., Hassan et al., 2009; Scheckman and McMurry, 2011).

The shape of atmospheric aerosols can evolve under ambient conditions (Li et al., 2016). Particle sphericity increases by deliquescence of particles and condensation of gaseous precursors on non-spherical particles (Husar and Whitby, 1973; Ueda et al., 2016). Conversely, a high concentration of primary particles in the atmosphere leads to collisions, resulting in the formation of aggregate particles (Kim et al., 2015). Inorganic materials are crystallized under certain conditions; thus, they are an agent of change in particle shape (Hansson et al., 1998). The morphological features of ambient particles have been widely analyzed with electron microscopy, which generally characterized two categories of particles with distinct shapes, namely, (a) primary particles, e.g., such as fresh soot, mineral dust, and dry sea-salt particles (Zhang et al., 2006; Liu et al., 2017) with non-spherical shapes, and (b) secondary particles, including sulfate, nitrate, and organics, which are condensation products of gaseous precursor 
compounds and products of aqueous-phase reactions, with typically near-spherical shapes. However, non-spherical particles have also been reported in the case of the coagulation of ammonium sulfate particles and secondary formation of sulfate, nitrate, and organics on soot particles (Slowik et al., 2007; Coz et al., 2008; Ueda et al., 2011, 2016).

Although electron microscopy is a powerful tool to determine the morphology of particles, it is not capable of in situ real-time measurements. In addition, the morphology of particles potentially changes during sampling, storage, and analysis (typically under low-pressure conditions) (Matthias and Ruprecht, 1994; Chen et al., 2017). For these reasons, several approaches have been proposed as alternatives for the estimate of particle shape and morphology. A single-particle soot photometer (SP2; Droplet Measurement Technologies) is an instrument useful in estimating the mixing state and morphology of black carbon (BC)-containing particles in real time through the measurement of the temporal evolution of scattered and incandescent light from these particles (Schwarz et al., 2006; Moteki and Kondo, 2007; Sedlacek et al., 2012). A shortcoming of this method is that information about the shape of non-BC-containing particles could not be obtained. Recently, polarization-based photothermal interferometry (PTI) has been applied to the characterization of absorbing aerosols though PTI could not provide morphological information about BC (Lee and Moosmüller, 2020). The measurements of effective density distributions can also provide information about the shape and mixing states of the ensembles of particles (DeCarlo et al., 2004). Herein, the effective density is typically measured with the combination of differential mobility analyzer (DMA) and aerosol mass spectrometer (AMS) or aerosol particle mass analyzer (APM) (McMurry et al., 2002; Slowik et al., 2004) via a comparison of the mobility diameter (obtained using DMA) with the aerodynamic diameter (obtained using AMS) or particle mass (obtained using APM). In addition, the shape factor of particles can also be obtained from the particle-size dependence of the effective density (DeCarlo et al., 2004).

Light scattering has also been used for the estimation of the mixing state of particles. Kobayashi et al. (2014) have used a polarization optical particle counter (POPC) to categorize aerosol types (mineral dust, air pollution, and seasalt particles) using the magnitude and polarization ratio of scattered light at a fixed scattering angle. A recently developed polar nephelometer $(\mathrm{PN})$ can measure the scattering angular distribution of individual particles suspended in the air in real time. It further shows the potential of a single-particle PN to distinguish spherical and non-spherical particles (Nakagawa et al., 2016): An estimation of the sphericity of individual particles can provide information about the mixing state of particles.

This study focused on the application of the PN instrument for ambient aerosol observation, with the objective of estimating the sphericity and mixing state of particles, during summer in an urban area in Japan. Specifically, the estimated sphericity is compared with meteorological parameters, gaseous compounds, and particulate chemical composition to examine the possible factors that can affect the particle sphericity.

\section{EXPERIMENTAL}

Observations were conducted at the Higashiyama campus of Nagoya University $\left(35^{\circ} 09^{\prime} \mathrm{N}, 136^{\circ} 58^{\prime} \mathrm{E}, 60 \mathrm{~m}\right.$ a.s.1.), Nagoya, Japan, from July 1, 2015, to July 16, 2015 (the time zone used in this paper is Japan Standard Time). Nagoya is a large city with a population of about 2.3 million and is located near the center of the main island of Japan. The sampling site is mainly surrounded by residential areas, and an industrial area is located south and west of the site (Nakayama et al., 2014). Ambient particles were sampled at the $8^{\text {th }}$ floor of a building and were dried using a diffusion dryer with silica gel. The particles were then introduced alternately to a bypass line and a thermodenuder (TD) line maintained at $300^{\circ} \mathrm{C}$, respectively, for the measurement of ambient particles and refractory particles after the evaporation of volatile compounds, respectively. The lines were switched every $15 \mathrm{~min}$ using ball valves. The same type of TD was used as in our previous study (Guo et al., 2014; Nakayama et al., 2014). Large fractions of organic matter, sulfate, nitrate, and ammonium in submicrometer particles were expected to evaporate during passing through the TD at $300^{\circ} \mathrm{C}$ (Nakayama et al., 2014). Downstream particles with a mobility diameter of $500 \mathrm{~nm}$ were selected using a DMA (Model 3080; TSI Inc.) and were detected by the single-particle PN. Note that the mobility diameter $(500 \mathrm{~nm})$ chosen in this study is close to the mass mean diameter $(462 \mathrm{~nm})$ during the observation.

Nakagawa et al. (2016) have presented a detailed description of the PN instrument and its performance, and only a brief description about the instrument is provided here. The PN measured light intensities scattered by a stream of particles intersecting a $300-\mathrm{mW}$ laser beam at 532-nm wavelength from an $\mathrm{Nd}$ :YAG laser. The particles were focused on the center of the measurement plane by a sheath flow of filtered air. Scattering angular distributions from $11.7^{\circ}$ to $168.3^{\circ}$ (with an angular resolution of $7.8^{\circ}$ ) in planes parallel and perpendicular to the polarization of the incident laser beam were simultaneously measured using 21 photodiode detectors placed in each plane. Each particle typically passed through the laser beam within $0.1 \mathrm{~s}$. The detection of scattered light at $100 \mathrm{~Hz}$ allowed each single particle to be detected at least when particles larger than $300 \mathrm{~nm}$ in mobility diameter were introduced into our PN.

The size distribution of particles between 14.1 and 736.5 $\mathrm{nm}$ were measured at an interval of 5 min using an SMPS (Models 3080 and 3775; TSI Inc.) deployed at another building on campus, where the inlet was placed on the rooftop above the $4^{\text {th }}$ floor. The sample air passed through a $\mathrm{PM}_{2.5}$ cyclone (URG-2000-30EH; URG Corp.) and diffusion dryers. At the $8^{\text {th }}$ floor of the building where the PN instrument was deployed, another SMPS (Models 3080 and 3772; TSI Inc.) was operated for the sample air that passed through the $\mathrm{PM}_{1}$ cyclone (URG-2000-30EHB; URG Corp.), diffusion driers, and another TD maintained at $300^{\circ} \mathrm{C}$. The size distributions of particles between 14.1 and $736.5 \mathrm{~nm}$ that passed through another TD were measured at an interval of 5 min together with those of the particles that did not pass through the TD.

Non-refractory $\mathrm{PM}_{1}$ components, i.e., organics, sulfate, 
nitrate, ammonium, and chloride, were measured using a high-resolution time-of-flight aerosol mass spectrometer (HR-ToF-AMS; Aerodyne Research) by introducing a part of the sample air that passed through the above-mentioned $\mathrm{PM}_{2.5}$ cyclone and diffusion dryers. The mass concentrations of these non-refractory components were obtained every 15 min via mass spectra analysis in V-mode. Organic mass fractions of mass-to-charge ratio $(\mathrm{m} / \mathrm{z}) 44$ (fragment ions of non-acid oxygenates and hydrocarbon-line organics) ( $\mathrm{Ng}$ et al., 2011)) and $m / z, 43$ (fragment ions of carbonyl and alkyl ions), named $f_{44}$ and $f_{43}$, respectively, were also calculated from the AMS mass spectra in $\mathrm{V}$-mode. The $f_{44}$ and $f_{43}$ are known to indicate degree of oxidation of organics ( $\mathrm{Ng}$ et al., 2011; Canagaratna et al., 2015). The AMS data were available only from 16:15 of July 1 to 10:54 of July 7 due to maintenance for the instrument.

At the $8^{\text {th }}$ floor of the building where the PN instrument was deployed, the absorption coefficients at $526 \mathrm{~nm}$ for submicrometer particles were measured once every minute using a single-wavelength Particle Soot Absorption Photometer (1- $\lambda$ PSAP; Radiance Research) by introducing a part of the sample air that passed through the TD for the SMPS. Accordingly, the mass concentration of equivalent black carbon (eBC) was calculated from the absorption coefficient using the method reported by Kondo et al. (2009). Note that the influence of the scattering of co-existing particles could be minimized by evaporating the non-refractory aerosol compounds by using the TD before collecting BC.

Meteorological data of relative humidity $(\mathrm{RH})$ and total solar irradiance were obtained from the Nagoya Local Meteorological Observatory of Japan Meteorological Agency (http://www.jma-net.go.jp/nagoya/), which is located approximately $2.0 \mathrm{~km}$ northwest from the observation site. The concentrations of gaseous species, including ozone $\left(\mathrm{O}_{3}\right)$ and nitrogen oxides ( $\mathrm{NO}$ and $\mathrm{NO}_{2}$ ), were obtained at the nearest air-quality monitoring station (Takikawa Elementary School) of the Atmospheric Environmental Regional Observation System (AEROS) operated by the Ministry of Environment, Japan (http://soramame.taiki.go.jp), which is located approximately $1.4 \mathrm{~km}$ southeast from the observation site. Potential ozone (PO) concentration, which is often used as an indicator of photochemical ozone production during daytime, was calculated from the concentrations of $\mathrm{O}_{3}, \mathrm{NO}_{2}$, and $\mathrm{NO}_{x}\left(\mathrm{NO}+\mathrm{NO}_{2}\right)$ using the following equation (Sadanaga et al., 2012):

$[\mathrm{PO}]=\left[\mathrm{O}_{3}\right]+\left[\mathrm{NO}_{2}\right]-0.1\left[\mathrm{NO}_{\mathrm{x}}\right]$

\section{RESULTS AND DISCUSSION}

\section{Particle Sphericity Index}

Fig. 1 shows a typical example of the angular distributions of light scattering for incident light polarized parallel (open symbols) and perpendicular (filled symbols) to the scattering plane for an ambient particle with 500-nm mobility diameter measured without passing through the TD. The solid and dashed lines represent the results of the simulation based on the Lorentz-Mie theory for a spherical particle with a refractive index (RI) of 1.52 at a wavelength of $532 \mathrm{~nm}$. The

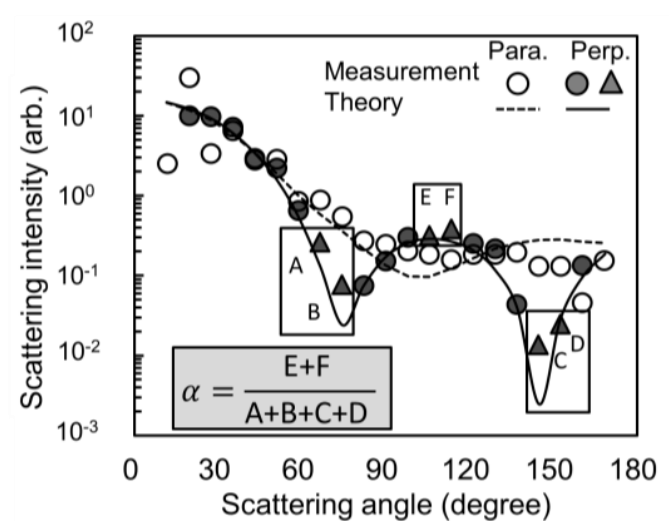

Fig. 1. Example of the angular distributions of light scattering for incident light polarized parallel (open symbols) and perpendicular (filled symbols) to a non-heated particle with a mobility diameter of $500 \mathrm{~nm}$ measured at 12:49 on July 3, 2015. The solid and dashed lines represent the results of simulations based on the Lorentz-Mie theory for a spherical particle with an RI of 1.52 at $532 \mathrm{~nm}$. Parameter $\alpha$ is defined as $\alpha=(\mathrm{E}+\mathrm{F}) /(\mathrm{A}+\mathrm{B}+\mathrm{C}+\mathrm{D})$, where the values of $\mathrm{A}, \mathrm{B}$, $\mathrm{C}, \mathrm{D}, \mathrm{E}$, and $\mathrm{F}$ are scattering intensities at $66.5^{\circ}, 74.3^{\circ}$, $114.8^{\circ}, 152.6^{\circ}, 106.7^{\circ}$, and $113.4^{\circ}$, respectively, as shown with filled triangles.

detection efficiency and angular resolution of each sensor were considered in the simulation, as described in our previous study (Nakagawa et al., 2016). As expected theoretically for spherical particles, the local minima were observed for scattering angular distribution on incident light perpendicular to the scattering plane at roughly $75^{\circ}$ and $145^{\circ}$. In addition, these local minima were expected to be unclear for nonspherical particles (Nakagawa et al., 2016). Thus, the particle sphericity was estimated from the depths of these local minima, using a new index $(\alpha)$, defined as follows:

$$
\alpha=\frac{E+F}{A+B+C+D}-=\frac{\mathrm{a}+\mathrm{b}}{\mathrm{A}+\mathrm{B}+\mathrm{C}+\mathrm{D}}
$$

where A, B, C, D, E, and F represent light-scattering signal intensities for the perpendicular data at $66.5^{\circ}, 74.3^{\circ}, 144.8^{\circ}$, $152.6^{\circ}, 106.7^{\circ}$, and $113.4^{\circ}$, respectively. The scattering angles close to both $75^{\circ}$ and $145^{\circ}$, which are supposed to give local minima for spherical particles, were selected as angles for A, B, C, and D, and the angles close to the middle of $75^{\circ}$ and $145^{\circ}$ were selected as angles for $\mathrm{E}$ and $\mathrm{F}$.

For typical ambient particles consisting of organics and/or inorganic salts (e.g., ammonium sulfate and ammonium nitrate), the real-part values of RI at $532 \mathrm{~nm}$ were expected between 1.40 and 1.60 under dry conditions (Toon et al., 1976; Gosse et al., 1997; Schmid et al., 2009; Moise et al., 2015). The effect of these RI values on $\alpha$ was examined via simulation based on the Lorentz-Mie theory, assuming spherical particles. Fig. S1 (in the supporting information) describes the trend of $\alpha$ values, which were expected to increase from 0.60 to 3.21 with the increase of the real part of RI from 1.30 to 1.49 and to decrease from 3.21 to 0.82 with the increase of the real part of RI from 1.49 to 1.70 . For 
typical ambient particles with a real part of RI between 1.40 and $1.60, \alpha$ values were expected to be larger than 1.80 under dry conditions, assuming spherical particles.

Fig. S2 shows the dependences of $\alpha$ value on the imaginary part of a complex RI for a real part of $1.4,1.5$, and 1.6. The imaginary-part values for organics and/or inorganic salts (e.g., ammonium sulfate and ammonium nitrate) are known to be typically smaller than 0.01 (Laskin et al., 2015; Moise et al., 2015). The $\alpha$ values are expected to increase slightly (up to 0.1 ) with increasing the imaginary-part values from 0 to 0.01 (Fig. S2(b)). However, the $\alpha$ values for strongly light-absorbing particles, including BC typically having the imaginary-part values around 0.8 (Bond and Bergstrom 2006), decrease to approximately 0.7 even if particles are spherical in shape (Fig. S2(a)).

Accordingly, the $\alpha$ values for soot (generated during the combustion of propane) and sodium chloride $(\mathrm{NaCl})$ with a mobility diameter of $500 \mathrm{~nm}$ were calculated using experimentally obtained scattering angular distribution data in our previous study (Nakagawa et al., 2016). The results of electron microscope analyses indicated that soot had aggregate structures with small spherules (diameter $<100 \mathrm{~nm}$ ) and that $\mathrm{NaCl}$ was cubical in shape with rounded edges and corners (Nakagawa et al., 2016). Specifically, the mean values $( \pm 1 \sigma)$ of $\alpha$ for the soot and $\mathrm{NaCl}$ were $0.35( \pm 0.02)$ and 0.79 $( \pm 0.26)$, respectively, which were significantly smaller than the values simulated earlier for typical ambient spherical particles without strong light absorption $(\alpha>1.80)$. These results indicate that $\alpha$ can be an indicator for distinguishing spherical and non-spherical particles in the atmosphere. It should be noted that, in case of soot particles, a large imaginarypart would also contribute to the small $\alpha$, as discussed above

\section{Distribution of Particle Sphericity Index}

Fig. 2 shows the histograms of $\alpha$ for all detected particles that passed through the TD and ones that did not pass through it at $300^{\circ} \mathrm{C}$ during the observation period. Because size selection was performed after heating, removal or shrinkage of particles with an original diameter of $500 \mathrm{~nm}$ and shrinkage of particles with original diameters greater than $500 \mathrm{~nm}$ to the diameter of $500 \mathrm{~nm}$ govern the number of particles detected after the passage through the TD. The ratio of the total number of detected particles that passed through the TD to those of unheated particles that did not pass through the TD was 0.08 . This ratio is consistent with the corresponding value $(0.08)$ obtained from the particlesize distributions measured simultaneously using the two SMPSs, where the value was the ratio of the mean number concentration of heated particles to that of unheated particles in the mobility diameter range from 478 to $533 \mathrm{~nm}$. This agreement indicated the similar detection efficiencies of the PN for particles that passed and did not pass through the TD, regardless of particle sphericity at least for 500-nm particles. This finding is important when $\alpha$ is applied for the quantitative estimation of the mixing state of particles.

Fig. 2 shows that ambient particles without passing through the TD typically had two distinct peaks at around $\alpha$ $=0.25$ (Peak 1) and $\alpha=1.25$ (Peak 2), indicating that the aerosols were external mixtures of at least two types of

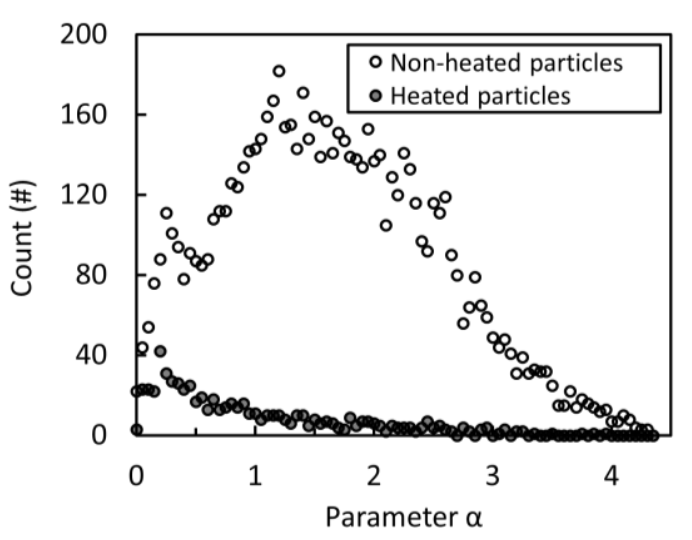

Fig. 2. Histogram of $\alpha$ for all non-heated (open circles) and heated (filled circles) ambient particles with a mobility diameter of $500 \mathrm{~nm}$ observed in this study. The heated ambient particles were measured after the passage of the particles through a thermodenuder maintained at $300^{\circ} \mathrm{C}$ prior to size selection.

particles with relatively high and low sphericities. Note that, although these particles were categorized into two groups using an $\alpha$ value (0.5) for local minimum for non-heated particles in Fig. 2, it does not necessarily mean that all particles with $\alpha>0.5$ are highly spherical in shape, considering the $\alpha$ value for $\mathrm{NaCl}$ particles (0.79). The particles with relatively high sphericity $(\alpha>0.5)$ were found dominant at a mean fraction of $89 \%$, which was calculated from the ratio of total number of particles with $\alpha>0.5$ to all detected particles when particles did not pass through the TD. When heated through the TD, the number of particles at $\alpha=0.25$ was reduced to one-third of the initial number, and no clear peak corresponding to the particles with high sphericity was observed. In this case, particles with low sphericity $(\alpha<0.5)$ became dominant with a mean fraction of $58 \%$, which was calculated from the ratio of total number of particles with $\alpha$ $<0.5$ to all detected particles when particles passed through the TD. As mentioned above, the number of particles after passing through the TD could also decrease due to shrinkage by the heating if the number of particles decreases with increasing diameter above $500 \mathrm{~nm}$. However, the shape of the histogram of $\alpha$ should not change after shrinkage if all particles with different $\alpha$ values shrink similarly by heating. These results indicated that particles consisting of refractory compounds, which do not evaporate at $300^{\circ} \mathrm{C}$, were more likely to have low sphericity.

During summer in a different year (2011) in Nagoya, Nakayama et al. (2014) measured the density distributions of particles with mobility diameters of 100 and $200 \mathrm{~nm}$ using the DMA-APM-CPC system after passing through the TD maintained at $300^{\circ} \mathrm{C}$. They reported that most of the refractory particles that remained after passage through the TD had small effective densities, and most non-spherical particles with small effective densities were not removed after passing through the TD. Hence, they suggested that the non-spherical particles were mainly refractory $\mathrm{BC}$ particles with aggregate structures. By contrast, a non-negligible fraction of particles with low sphericity $(\alpha<0.5)$ was removed (or shrunk) after 
passage through the TD in this study. Such difference was believed to be caused by the difference in selected particle sizes between this study and that of Nakayama et al. (2014). In this study, relatively large particles with a diameter of 500 $\mathrm{nm}$ were selected, and particles generated through the coagulation of ammonium sulfate particles and/or secondary formation of sulfate, nitrate, and organics on soot particles may have contributed to the refractory non-spherical particles observed herein (Slowik et al., 2007; Coz et al., 2008; Ueda et al., 2011, 2016).

The ratio of the total number of particles with relatively high sphericity $(\alpha>0.5)$ with passing through the TD to that without passing through the TD was $5.1 \%$ in this study, whereas during summer in 2011 the mass fractions remaining for the organics and sulfate (major non-refractory materials) in fine particles after passing through the TD were recorded at $8 \pm 2 \%$ and $6 \pm 3 \%$, respectively (Nakayama et al., 2014). In this study, the mass mean diameter estimated from the size distribution was $462 \mathrm{~nm}$, which is similar to the particle diameter $(500 \mathrm{~nm})$ selected for the PN. Such similarity in size is considered to bring consistency between the number fraction remaining for particles with relatively high sphericity $(\alpha>0.5)$ with a diameter of $500 \mathrm{~nm}$ obtained in this study and the mass fractions remaining for the major refractory materials reported by Nakayama et al. (2014).

\section{Fraction of Particles with Low Sphericity}

Possible factors contributing to the fraction of particles with low sphericity are discussed in this section. Fig. 3 presents a time series of the 3-h-averaged fraction of particles with low sphericity, RH, solar irradiance, and mass fraction of eBC. The $3 \mathrm{~h}$ is typically needed to detect enough particles by the PN for the discussion. Here, the mass fraction of eBC to total particle mass was estimated based on the PSAP and SMPS data assuming spherical particles and a particle density of $1.4 \mathrm{~g} \mathrm{~cm}^{-3}$.

The focus was on the difference in two characteristic periods: July 4-8 (Period A) and July 11-13 (Period B). During Period A, RH was extremely high (near $100 \%$ during nighttime and $>75 \%$ even during daytime), whereas solar radiation was relatively low $\left(0.57-1.12 \mathrm{MJ} \mathrm{m}^{-2}\right)$. In contrast during Period B, RH was relatively low (down to 54-63\% during daytime), whereas solar radiation was high (1.99$\left.2.67 \mathrm{MJ} \mathrm{m}^{-2}\right)$. Fig. 4 shows the averaged diurnal variation of the fractions of particles with low sphericities $(\alpha<0.5)$ and mass fractions of eBC for the two periods. On average, the fraction of particles with low sphericity $(\alpha<0.5)$ tended to be lower in Period B compared to that in Period A throughout the day. In the case of the mass fractions of $\mathrm{eBC}$, all averaged values in Period $B$ were lower than those in Period A. This result suggests a possible contribution of eBC to the particles with low sphericity $(\alpha<0.5)$. However, the fractions of particles with low sphericity were high during nighttime and low during daytime in both periods (Fig. 4(a)), as opposed to the trends of the diurnal variations of the mass fractions of eBC, which were high during daytime and low during nighttime, for both periods. A possible interpretation of the results is that the fraction of non-spherical particles with $\alpha<0.5$ decreased due to greater photochemical formation of nearly spherical particles during daytime. Some of these secondarily formed components would contribute to the coating of eBC and led to the decrease of the fraction of nonspherical refractory particles with $\alpha<0.5$ during daytime, especially in Period B (when solar irradiation was high).

\section{Sphericity of Non-refractory Particles}

As discussed above most particles with relatively high $\alpha$ values $(\alpha>0.5)$ consisted of non-refractory materials. Possible factors contributing to the mean $\alpha$ value of particles in the group with relatively high sphericity $(\alpha>0.5)$ are examined in this section. In Fig. 3, the time series of the 3h-averaged $\alpha$ value of particles with $\alpha>0.5$ and mass fractions of major particle compounds are presented. The contribution of the chemical composition of the particles to non-refractory particles was investigated via the analyses of the AMS data available for the period July 2-7. This period was divided into two groups, namely, Group I (July 2, 3, and 5) and Group II (July 4, 6, and 7) based on the RH data during daytime. Group II yielded higher average $\mathrm{RH}$ values in the daytime between 06:00 and 18:00 (89\%, 92\%, and 89\% on July 4, 6, and 7, respectively) than Group I (65\%, 83\%, and $83 \%$ on July 2, 3, and 5, respectively), as shown in Fig. 3(b).

Figs. 5(a) and 6(a) show the average diurnal variation of the mean $\alpha$ value of near-spherical particles for Group I and II, respectively. The averaged diurnal variations of $\mathrm{RH}, \mathrm{NO}_{x}$ and PO, $f_{43}$ and $f_{44}$, and the mass fractions of major nonrefractory materials are also shown in panels (a), (b), (c), (d), respectively, in Figs. 5 and 6.

For Group I, the mean $\alpha$ values exhibited a minimum in the early morning $(\alpha=1.73$ at $04: 00)$ and then gradually increased to a maximum in the evening ( $\alpha=1.94$ at 19:00) (Fig. 5(a)). The PO concentrations were low from midnight to noon and then increased from noon reaching to its maximum (69 ppbv) at 16:00 (Fig. 5(b)). The $\mathrm{NO}_{x}$ concentrations were relatively high during daytime, which is likely due to traffic emissions (Fig. 5(b)). The aerosol organic materials constituted dominant mass fractions (approximately 50\%) throughout the day (Fig. 5(c)). Although the mass fractions of the major non-refractory materials (organics, sulfate, nitrate, and ammonium) did not show significant diurnal variations (Fig. 5(c)), the $f_{44}$ values (an indicator of the degree of oxidation of organics) gradually increased during daytime, and the $f_{43}$ values gradually decreased during daytime (Fig. 5(d)). The higher sphericity (higher $\alpha$ values) observed in the afternoon is possibly due to the photochemical formation and the aging processes of secondary aerosol components (mainly organic compounds) during daytime, considering the high PO and $f_{44}$ values in the afternoon and relatively high solar radiation (with low $\mathrm{RH}$ ) during daytime in Group I.

For Group II, the mean $\alpha$ values showed two peaks, one at $\alpha=1.84$ in the early morning at 04:00 and another at $\alpha=$ 1.88-1.90 between 10:00 and 16:00 (Fig. 6(a)). As in the case of Group I, the PO concentrations increased during daytime, reaching their maximum (54 ppbv) at 16:00 (Fig. 6(b)). The $\mathrm{NO}_{x}$ concentrations in Group II (on average, 20 ppbv) were higher than those in Group I (on average, 13 ppbv), which is particularly high in the afternoon (Fig. 6(b)), and this is 
(a)

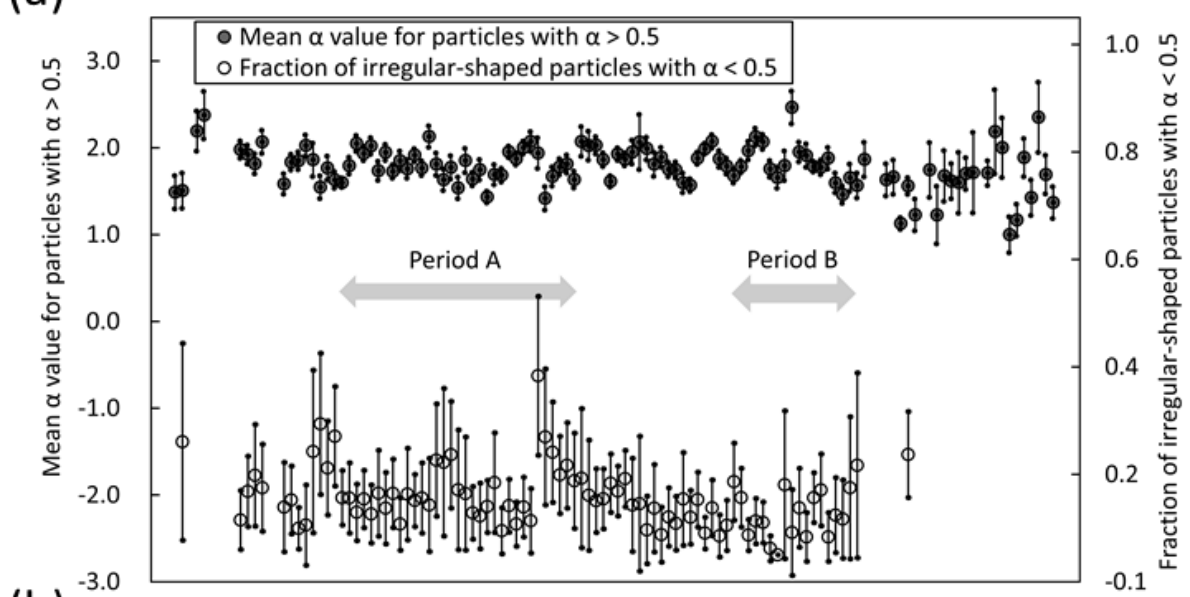

(b)

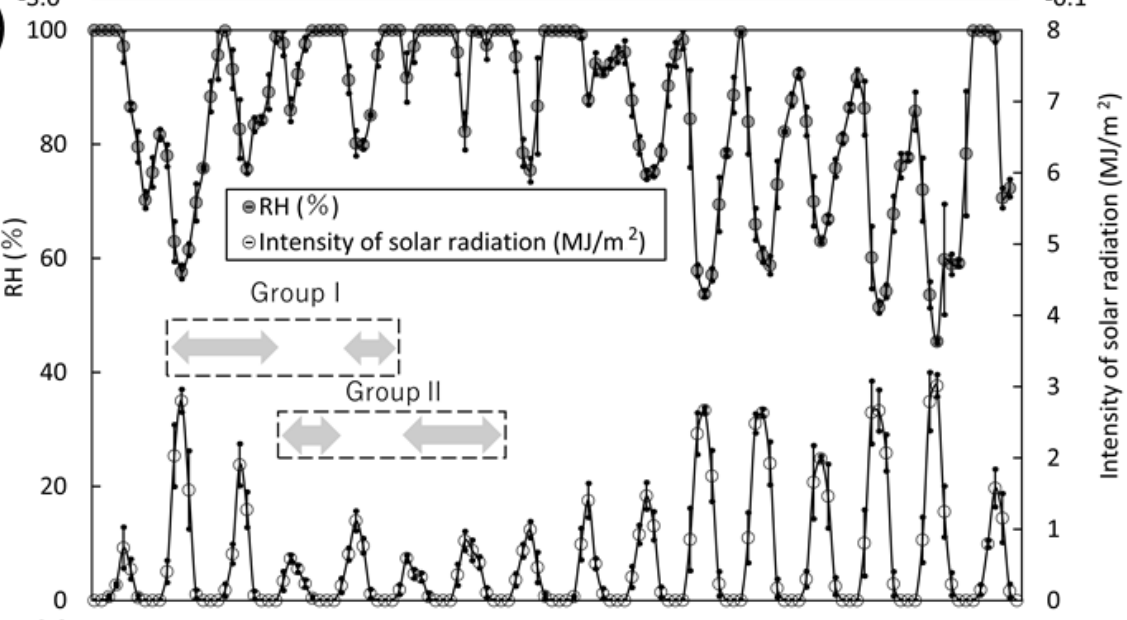

(c)

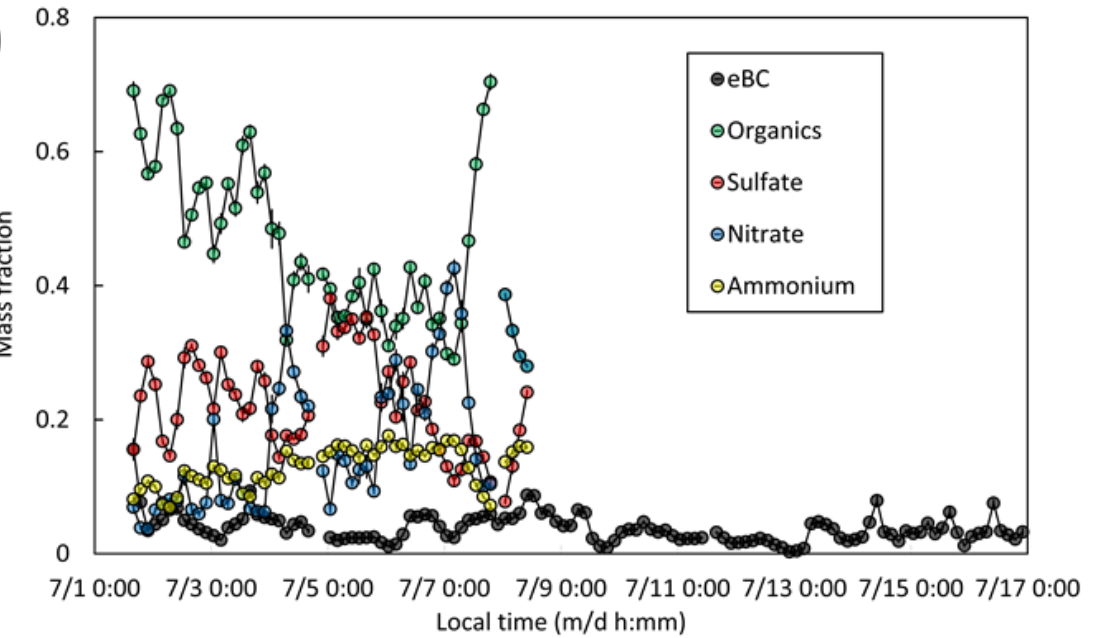

Fig. 3. Time series of (a) the 3-h mean $\alpha$ value for particles with $\alpha>0.5$ and the fraction of irregular-shaped particles with $\alpha<0.5$; (b) relative humidity and solar irradiance; and (c) mass fractions of organics, sulfate, nitrate, ammonium, and eBC. The mean $\alpha$ value and fraction of irregular-shaped particles were not calculated when the numbers of total and irregularshaped particles detected within the 3 -h period were less than five, respectively. The error bars represent $1 \sigma$ values.

likely due to accumulation under weaker wind conditions (with whole-day and afternoon averages of 1.5 and $1.6 \mathrm{~m} \mathrm{~s}^{-1}$, respectively) than those in Group I (with whole-day and afternoon averages of 2.1 and $2.7 \mathrm{~m} \mathrm{~s}^{-1}$, respectively) (Fig. S3). Although organics accounted for approximately $50 \%$ of the total particle masses in the afternoon, these mass fractions were lower than $40 \%$ from 22:00 to 07:00 (Fig. 6(c)). By contrast, the mass fractions of nitrate were high (0.29-0.32) from 22:00 to 07:00 (Fig. 6(c)). The $f_{44}$ values in Group II (on average, 0.14) were slightly lower than in Group I (on average, 0.16), and no significant increase in $f_{44}$ (decrease of $\left.f_{43}\right)$ in the afternoon was observed (Fig. 6(d)). The higher 
sphericity observed between 10:00 and 16:00 may be explained by the greater contributions of organics during daytime, although the contribution for a low mean $\alpha$ value at 19:00 remains unclear. Interestingly, another maximum of the sphericity was observed in the early morning when the mass fraction of nitrate was at its peak. Moreover, in Group II, water (a)

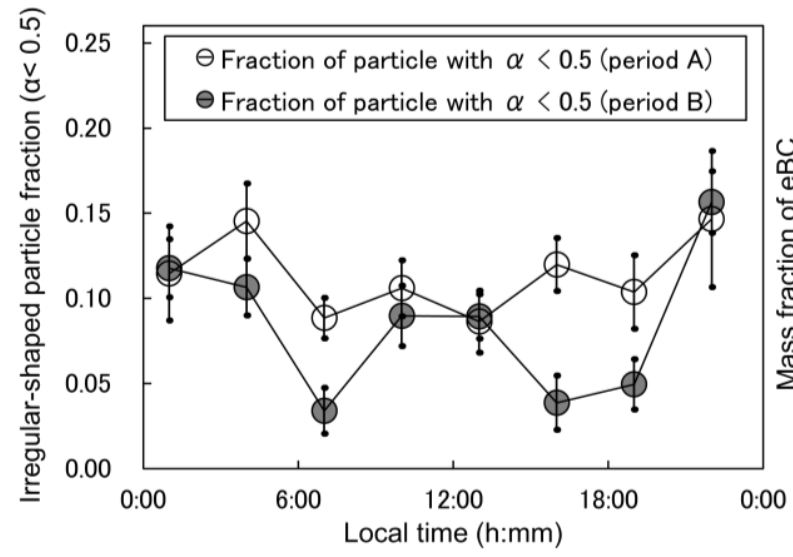

(b)

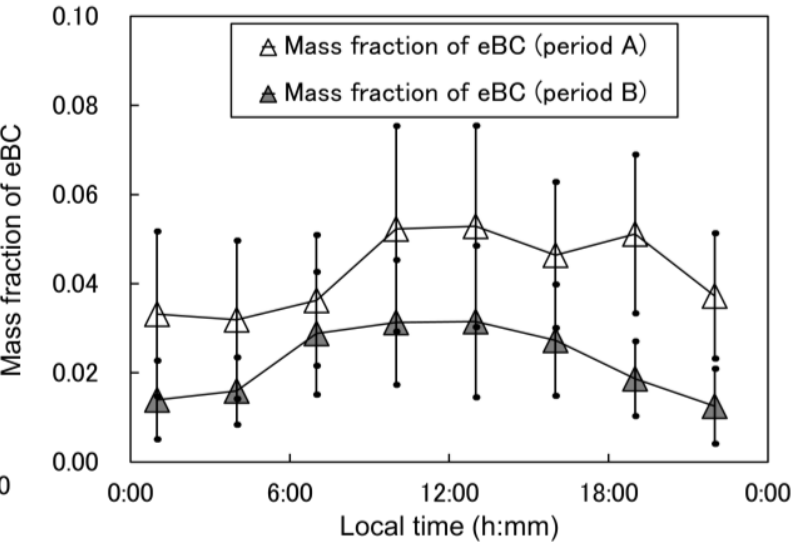

Fig. 4. Diurnal variations of (a) the fraction of irregular-shaped particles with $\alpha<0.5$ and (b) the mass fraction of equivalent black carbon (eBC) averaged over Period A (July 4-8; open symbols) and Period B (July 11-13; filled symbols). The error bars represent $1 \sigma$ values.

(a)

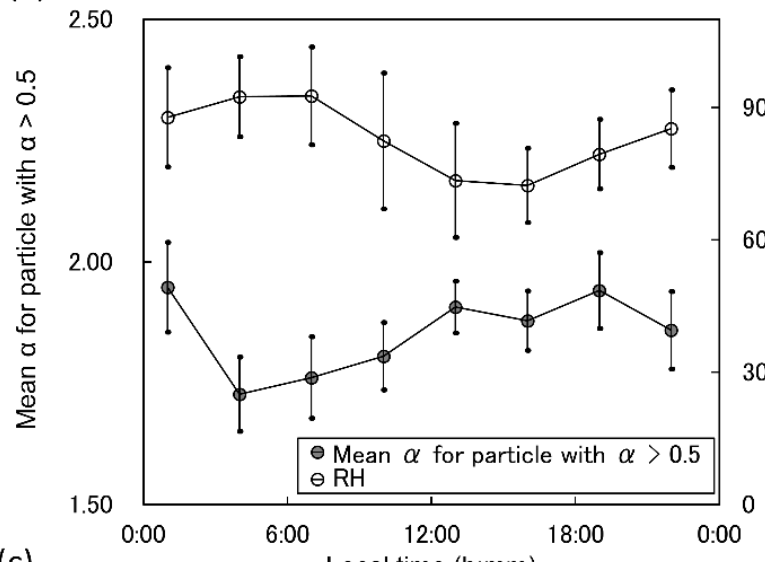

(c)

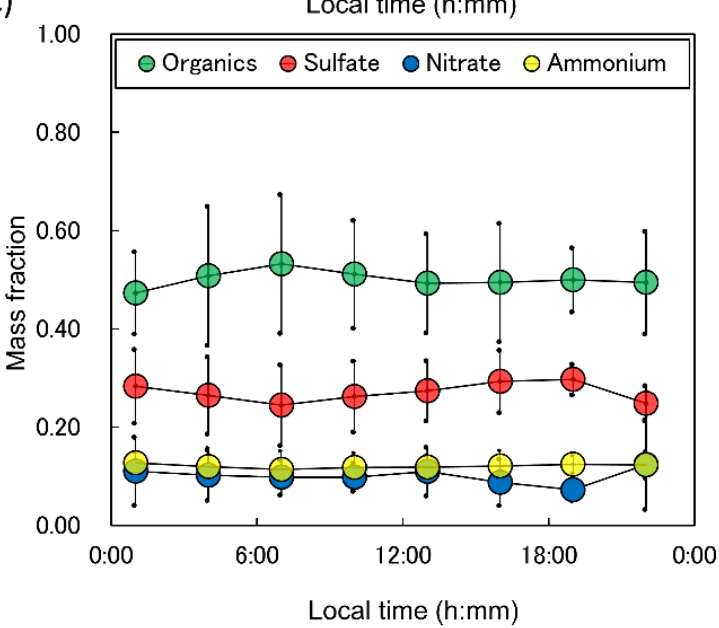

(b)

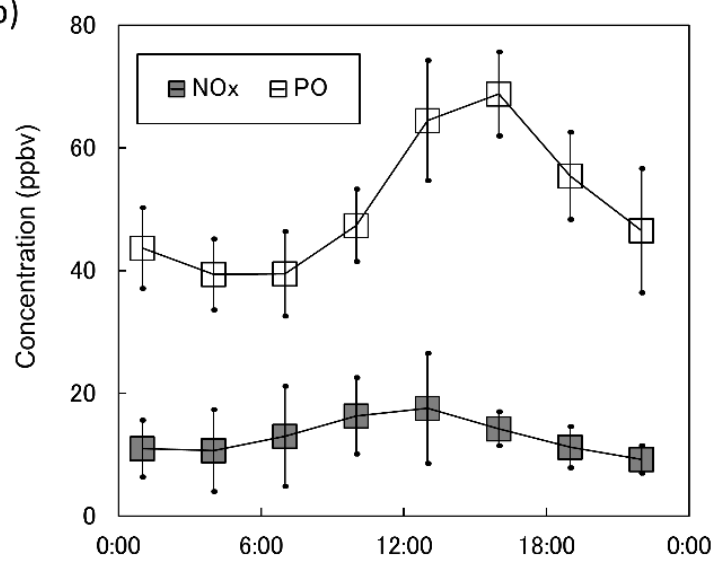

(d)

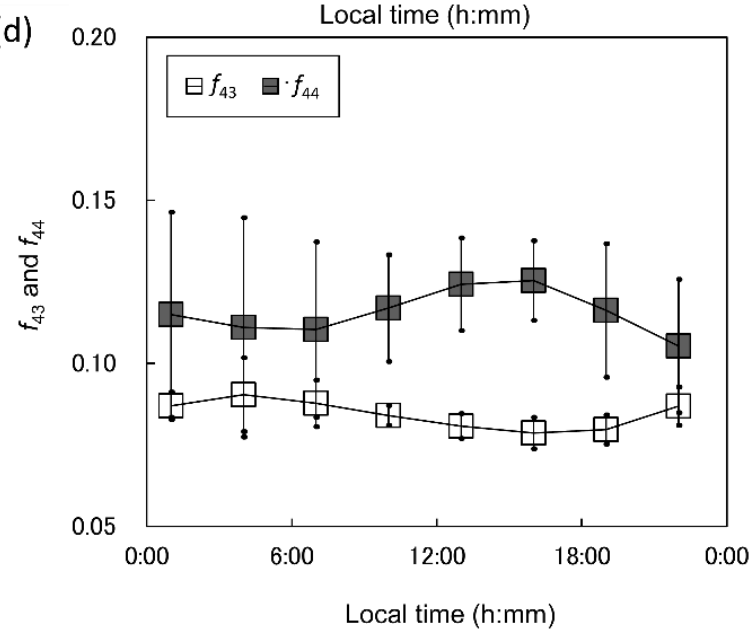

Fig. 5. Diurnal variations of (a) the mean $\alpha$ for particles with $\alpha>0.5$ and relative humidity (RH); (b) nitrogen oxides (NO $=\mathrm{NO}+\mathrm{NO}_{2}$ ) and potential ozone (PO); (c) mass fractions of organics, sulfate, nitrate, and ammonium; and (d) $f_{43}$ and $f_{44}$ values averaged over July 2, 3, and 5 (Group I). The error bars represent $1 \sigma$ values. 

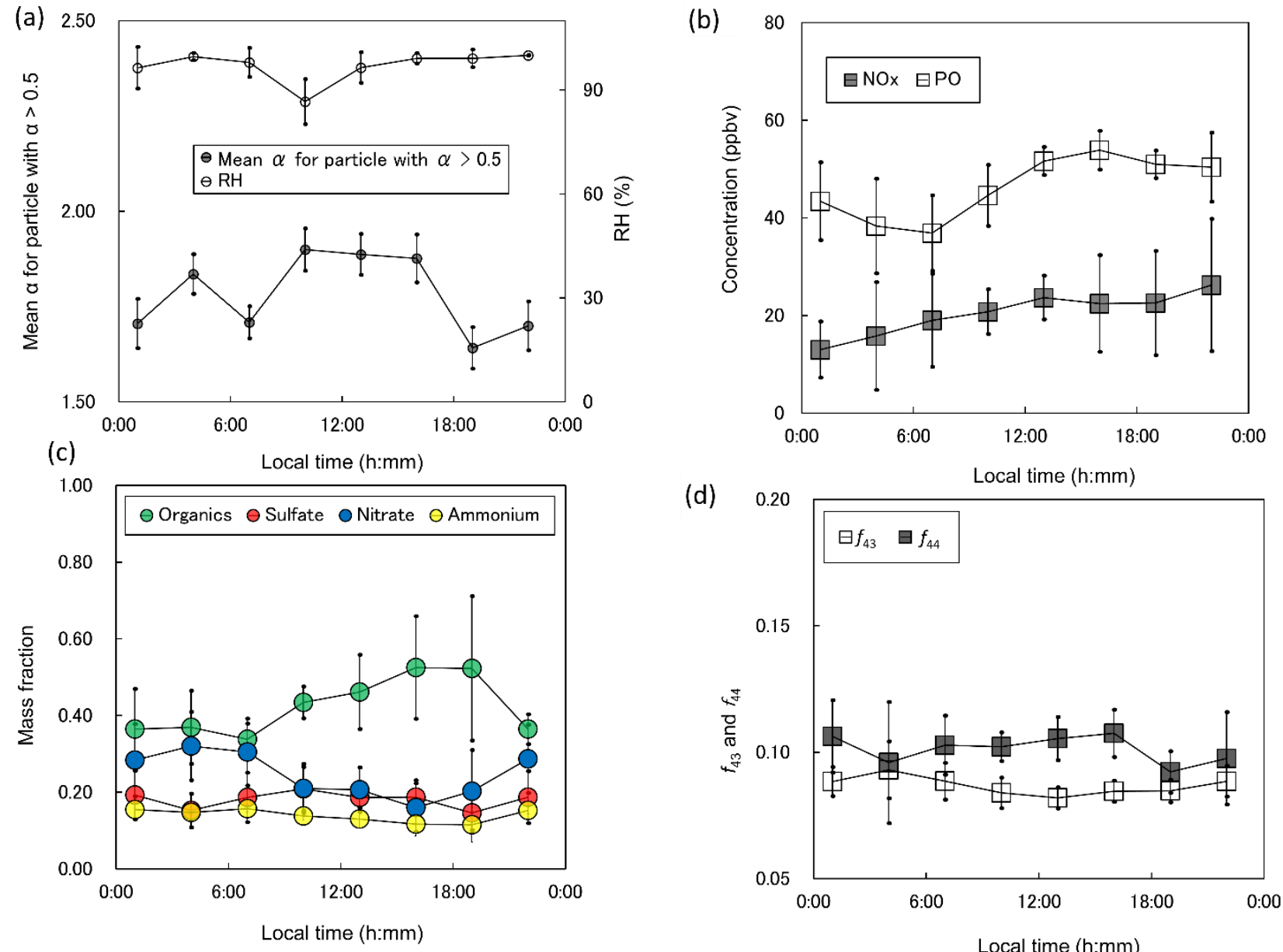

(d)

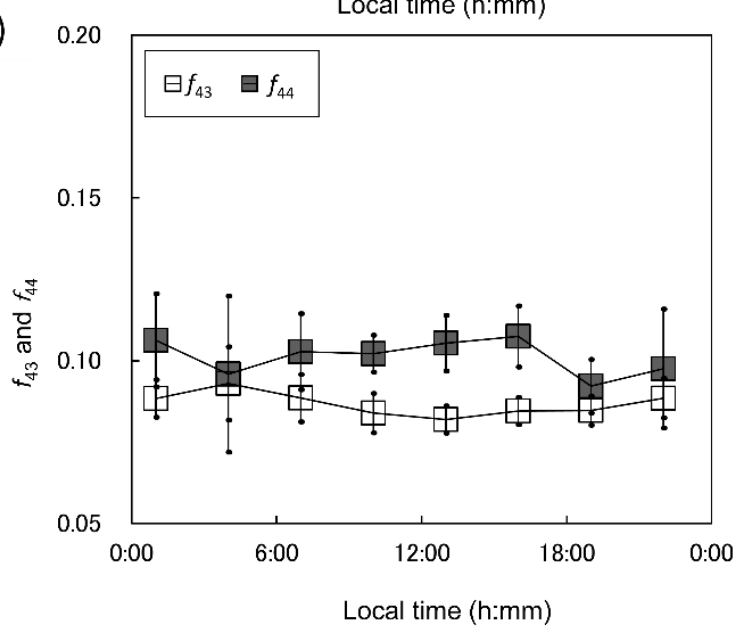

Fig. 6. Same as Fig. 5, but averaged over July 4, 6, and 7 (Group II).

vapor was almost saturated during nighttime (Fig. 6(a)). Therefore, nitrate formation in or on aqueous aerosol through the shift of gas-particle partitioning of $\mathrm{NH}_{4} \mathrm{NO}_{3}$ and $\mathrm{HNO}_{3}$ and/or hydrolysis of $\mathrm{N}_{2} \mathrm{O}_{5}$ was presumed to be enhanced under high-RH and low-temperature conditions from midnight to early morning, as widely observed in previous studies (e.g., Takahama et al., 2004; Wang et al., 2008), and potentially lead to the observed high sphericity of particles. Organic nitrate formation from the $\mathrm{NO}_{3}$ oxidation of volatile organic compounds might have also contributed to the enhancement of nitrate in the early morning (e.g., Yu et al., 2018). In addition, possible contribution of compaction of eBC by cloud processing under high-RH conditions also cannot be ruled out (Bhandari et al., 2019). Note that the amplitudes of the averaged diurnal variations of $\alpha$ value discussed in this section were less significant compared to the effect of the RI values (Fig. S1), and therefore, possible contribution of the diurnal variation of RI for non-refractory particles also cannot be ruled out.

\section{SUMMARY}

We utilized a home-made PN to measure the lightscattering angular distributions of thermodenuded and nonthermodenuded individual particles with a mobility diameter of $500 \mathrm{~nm}$ during summer at an urban site in Nagoya, Japan. Estimating the sphericities based on the depths of the local minima in the scattering angular distributions, we found the non-thermodenuded ambient particles to be external mixtures comprising at least two types of particles, one with relatively high and the other with relatively low sphericity. Although the TD, which maintained a temperature of $300^{\circ} \mathrm{C}$, removed most of the particles displaying high sphericity, it left approximately a third of the ones displaying low sphericity.

A smaller fraction of low-sphericity particles and a smaller mass fraction of eBC were observed when the solar irradiation was high (Period B). Additionally, the lowsphericity particles exhibited high mass fractions during nighttime and low mass fractions during daytime, especially when the RH was low (also Period B) - the opposite of the trend expected from the diurnal variation in the $\mathrm{BC}$ fraction. The proportion of these particles decreased during the day, possibly owing to the photochemical formation of secondary aerosol, including nearly spherical particles, and components that coated the $\mathrm{eBC}$ particles.

The sphericity of non-refractory particles increased during the daytime on days with relatively low RH (Group I) as well as those with relatively high RH (Group II), indicating that the diurnal formation and aging processes of secondary aerosol components (mainly organic compounds) likely played 
crucial roles in this enhancement. On the days with high RH, a peak in sphericity also occurred during the early morning, which may have been caused by the formation of nitrate.

This research demonstrates the efficacy of employing angular distribution measurements of the light scattering from individual particles to estimate the sphericity in real time. However, as this pilot study interpreted a new type of data using an original single-particle PN, uncertainties are still present in our results. Further improvements to the instrument, and observational studies on particle-size-dependent sphericity, including its relationship with the chemical composition in different environments, are essential to better understanding the sphericity of atmospheric particles and identifying its controlling factors.

\section{ACKNOWLEDGMENTS}

This study was supported in part by the Grant-in-Aid for Scientific Research (KAKENHI 25701001, 16K12581, $16 \mathrm{H} 02936,16 \mathrm{H} 06305$, and 19H04240) from the Ministry of Education, Culture, Sports, Science and Technology (MEXT) of Japan and the joint research program of the Institute for Space-Earth Environmental Research, Nagoya University. The data used in this paper are available on request to the corresponding author.

\section{SUPPLEMENTARY MATERIAL}

Supplementary data associated with this article can be found in the online version at https://doi.org/10.4209/aaqr.2 020.01 .0023

\section{REFERENCES}

Bhandari, J., China, S., Chandrakar, K.K., Kinney, G., Cantrell, W., Shaw, R.A., Mazzoleni, L.R., Girotto, G., Sharma, N., Gorkowski, K., Gilardoni, S., Decesari, S., Facchini, M.C., Zanca, N., Pavese, G., Esposito, F., Dubey, M.K., Aiken, A.C., Chakrabarty, R.K., ... Mazzoleni, C. (2019). Extensive soot compaction by cloud processing from laboratory and field observations. Sci. Rep. 9: 1-12. https://doi.org/10.1038/s41598-019-48143-y

Bond, T.C. and Bergstrom, R.W. (2006). Light absorption by carbonaceous particles: An investigative review. Aerosol Sci. Technol. 40: 27-67. https://doi.org/10.1080/ 02786820500421521

Boucher, O., Randall, D., Artaxo, P., Bretherton, C., Feingold, G., Forster, P., Kerminen, V.M., Kondo, Y., Liao, H., Lohmann, U., Rasch, P., Satheesh, S.K., Sherwood, S., Stevens, B. and Zhang, X.Y. (2013). Clouds and aerosols. In Climate Change 2013: The Physical Science Basis. Contribution of Working Group I to the Fifth Assessment Report of the Intergovernmental Panel on Climate Change, Stocker, T.F., Qin, D., Plattner, G.K., Tignor, M., Allen, S.K., Boschung, J., Nauels, A., Xia, Y., Bexand, V. and Midgley, P.M. (Eds.), Cambridge University Press, Cambridge, United Kingdom and New York, NY, USA.

Canagaratna, M.R., Jimenez, J.L., Kroll, J.H., Chen, Q.,
Kessler, S.H., Massoli, P., Ruiz, L.H., Fortner, E., Williams, L.R., Wilson, K.R., Surratt, J.D., Donahue, N.M., Jayne, J.T. and Worsnop, D.R. (2015). Elemental ratio measurements of organic compounds using aerosol mass spectrometry: Characterization, improved calibration, and implications. Atmos. Chem. Phys. 15: 253-272. https://doi.org/10.5194/acp-15-253-2015

Chen, C., Enekwizu, O.Y., Ma, Y., Zakharov, D. and Khalizov, A.F. (2017). The impact of sampling medium and environment on particle morphology. Atmosphere 8: 162. https://doi.org/10.3390/atmos 8090162

China, S., Scarnato, B., Owen, R.C., Zhang, B., Ampadu, M.T., Kumar, S., Dzepina, K., Dziobak, M.P., Fialho, P., Perlinger, J.A., Hueber, J., Helmig, D., Mazzoleni, L.R. and Mazzoleni, C. (2015). Morphology and mixing state of aged soot particles at a remote marine free troposphere site: Implications for optical properties. Geophys. Res. Lett. 42: 1243-1250. https://doi.org/10.1002/2014GL062404

Coz, E., Artíñano, B., Robinson, A.L., Casuccio, G.S., Lersch, T.L. and Pandis, S.N. (2008). Individual particle morphology and acidity. Aerosol Sci. Technol. 42: 224232. https://doi.org/10.1080/02786820801958759

DeCarlo, P.F., Slowik, J.G., Worsnop, D.R., Davidovits, P. and Jimenez, J.L. (2004). Particle morphology and density characterization by combined mobility and aerodynamic diameter measurements. Part 1: Theory. Aerosol Sci. Technol. 38: 1185-1205. https://doi.org/10.1080/027868 290903907

Gosse, S.F., Wang, M., Labrie, D. and Chylek, P. (1997). Imaginary part of the refractive index of sulfates and nitrates in the 0.7-2.6- $\mu \mathrm{m}$ spectral region. Appl. Opt. 36: 3622-3634. https://doi.org/10.1364/AO.36.003622

Guo, X., Nakayama, T., Yamada, H., Inomata, S., Tonokura, K. and Matsumi, Y. (2014). Measurement of the light absorbing properties of diesel exhaust particles using a three-wavelength photoacoustic spectrometer. Atmos. Environ. 94: 428-437. https://doi.org/10.1016/j.atmosenv. 2014.05.042

Hansson, H.C., Rood, M.J., Koloutsou-Vakakis, S., Hämeri, K., Orsini, D. and Wiedensohler, A. (1998). $\mathrm{NaCl}$ aerosol particle hygroscopicity dependence on mixing with organic compounds. J. Atmos. Chem. 31: 321-346. https://doi.org/10.1023/A:1006174514022

Hassan, M.S., and Lau, R.W.M. (2009). Effect of particle shape on dry particle inhalation: Study of flowability, aerosolization, and deposition properties. AAPS PharmSciTech. 104: 1252. https://doi.org/10.1208/s12249009-9313-3

Husar, R.B. and Whitby, K.T. (1973). Growth mechanisms and size spectra of photochemical aerosols. Environ. Sci. Technol. 7: 241-247. https://doi.org/10.1021/es60075a003

Kim, H., Kim, J.Y., Kim, J.S. and Jin, H.C. (2015). Physicochemical and optical properties of combustiongenerated particles from a coal-fired power plant, automobiles, ship engines, and charcoal kilns. Fuel 161: 120-128. https://doi.org/10.1016/j.fuel.2015.08.035

Kobayashi, H., Hayashi, M., Shiraishi, K., Nakura, Y., Enomoto, T., Miura, K., Takahashi, H., Igarashi, Y., Naoe, H., Kaneyasu, N., Nishizawa, T. and Sugimoto, N. 
(2014). Development of a polarization optical particle counter capable of aerosol type classification. Atmos. Environ. 97: 486-492. https://doi.org/10.1016/j.atmosen v.2014.05.006

Kondo, Y., Sahu, L., Kuwata, M., Miyazaki, Y., Takegawa, N., Moteki, N., Imaru, J., Han, S., Nakayama, T. , Kim Oanh, N.T. , Hu, M. , Kim, Y.J. and Kita, K. (2009). Stabilization of the mass absorption cross section of black carbon for filter-based absorption photometry by the use of a heated inlet. Aerosol Sci. Technol. 43: 741-756. https://doi.org/10.1080/02786820902889879

Laskin, A., Laskin, J. and Nizkorodov, S.A. (2015). Chemistry of atmospheric brown carbon. Chem. Rev. 115: 4335-4382. https://doi.org/10.1021/cr5006167

Lee, J. and Moosmüller, H. (2020). Measurement of light absorbing aerosols with folded-Jamin photothermal interferometry. Sensors 20: 2615. https://doi.org/10.3390/ s20092615

Li, W.,Shao, L.,Zhang, D., Ro, C.U., Hu, M., Bi, X., Geng, H., Matsuki, A., Niu, H. and Chen, J. (2016). A review of single aerosol particle studies in the atmosphere of East Asia: morphology, mixing state, source, and heterogeneous reactions. J. Clean. Prod. 112: 1330-1349. https://doi.org/10.1016/j.jclepro.2015.04.050

Liu, L., Kong, S., Zhang, Y., Wang, Y., Xu, L., Yan, Q., Lingaswamy, A.P, Shi, Z., Lv, S., Niu, H., Shao, L., Hu, M., Zhang, D., Chen, J., Zhang, X. and Li, W. (2017). Morphology, composition, and mixing state of primary particles from combustion sources - crop residue, wood, and solid waste. Sci. Rep. 7: 5047. https://doi.org/10.103 8/s41598-017-05357-2

Matthias-Maser, S. and Jaenicke, R. (1994). Examination of atmospheric bioaerosol particles with radii $>0.2 \mu \mathrm{m}$. $J$. Aerosol Sci. 25: 1605-1613. https://doi.org/10.1016/00218502(94)90228-3

McMurry, P.H., Wang, X., Park, K. and Ehara, K. (2002). The relationship between mass and mobility for atmospheric particles: A new technique for measuring particle density. Aerosol Sci. Technol. 36: 227-238. https://doi.org/10.1080/027868202753504083

Moise, T., Flores, J.M. and Rudich, Y. (2015). Optical properties of secondary organic aerosols and their changes by chemical processes. Chem. Rev. 115: 44004439. https://doi.org/10.1021/cr5005259

Moosmuller, H., Chakrabarty, R.K. and Arnott, W.P. (2009). Aerosol light absorption and its measurement: A review. J. Quant. Spectrosc. Radiat. Transfer. 110: 844 878. https://doi.org/10.1016/j.jqsrt.2009.02.035

Moteki, N. and Kondo, Y. (2007). Effects of mixing state of black carbon measurement by laser-induced incandescence. Aerosol Sci. Technol. 41: 398-417. https://doi.org/10.108 0/02786820701199728

Nakagawa, M., Nakayama, T., Sasago, H., Ueda, S., Venables, D.S. and Matsumi, Y. (2016). Design and characterization of a novel single-particle polar nephelometer. Aerosol Sci. Technol. 50: 392-404. https://doi.org/10.1080/02786826. 2016.1155105

Nakayama, T., Ikeda, Y., Sawada, Y., Setoguchi, Y., Ogawa, S., Kawana, K., Mochida, M., Ikemori, F.,
Matsumoto, K. and Matsumi, M. (2014). Properties of light absorbing aerosols in the Nagoya urban area, Japan, in August 2011 and January 2012: Contributions of brown carbon and lensing effect. J. Geophys. Res. 119: 1272112739. https://doi.org/10.1002/2014JD021744

Ng, N.L., Canagaratna, M.R., Jimenez, J.L., Chhabra, P.S., Seinfeld, J.H. and Worsnop, D.R. (2011). Changes in organic aerosol composition with aging inferred from aerosol mass spectra. Atmos. Chem. Phys. 11: 6465-6474. https://doi.org/10.5194/acp-11-6465-2011

Sadanaga, Y., Sengen, M., Takenaka, N. and Bandow, H. (2011). Analyses of the ozone weekend effect in Tokyo, Japan: Regime of oxidant $\left(\mathrm{O}_{3}+\mathrm{NO}_{2}\right)$ production. Aerosol Air. Qual. Res. 12: 161-168. https://doi.org/10.4209/aaqr. 2011.07.0102

Scarnato, B.V., Vahidinia, S., Richard, D.T. and Kirchstetter, T.W. (2013). Effects of internal mixing and aggregate morphology on optical properties of black carbon using a discrete dipole approximation model. Atmos. Chem. Phys. 13: 5089-5101. https://doi.org/10.51 94/acp-13-5089-2013

Scheckman, J.H. and McMurry, P.H. (2011). Deposition of silica agglomerates in a cast of human lung airways: Enhancement relative to spheres of equal mobility and aerodynamic diameter. J. Aerosol Sci. 42: 508-516. https://doi.org/10.1016/j.jaerosci.2011.05.003

Schmid, O., Chand, D., Karg, E., Guyon, P., Frank, G.P., Swietlicki, E. and Andreae, M.O. (2009). Derivation of the density and refractive index of organic matter and elemental carbon from closure between physical and chemical aerosol properties. Environ. Sci. Technol. 43: 1166-1172. https://doi.org/10.1021/es800570p

Schwarz, J.P., Gao, R.S., Fahey, D.W., Thomson, D.S., Watts, L.A., Wilson, J.C. and Chung, S.H. (2006). Singleparticle measurements of midlatitude black carbon and light-scattering aerosols from the boundary layer to the lower stratosphere. J. Geophys. Res. 111: D16. https://doi.org/10.1029/2006JD007076

Sedlacek, A.J., Lewis, E.R., Kleinman, L., Xu, J. and Zhang, Q. (2012). Determination of and evidence for non-coreshell structure of particles containing black carbon using the Single-Particle Soot Photometer (SP2). Geophys. Res. Lett. 39: L06802. https://doi.org/10.1029/2012GL050905

Slowik, J.G., Cross, E.S., Han, J.H., Davidovits, P., Onasch, T.B., Jayne, J.T. and Moosmüller, H. (2007). An intercomparison of instruments measuring black carbon content of soot particles. Aerosol Sci. Technol. 41: 295314. https://doi.org/10.1080/02786820701197078

Slowik, J.G., Stainken, K., Davidovits, P., Williams, L.R., Jayne, J.T., Kolb, C.E., Worsnop, D.R., Rudich, Y., DeCarlo, P.F. and Jimenez, J.L. (2004). Particle morphology and density characterization by combined mobility and aerodynamic diameter measurements. Part 2: Application to combustion-generated soot aerosols as a function of fuel equivalence ratio. Aerosol Sci. Technol. 38: 12061222. https://doi.org/10.1080/027868290903916

Takahama, S., Wittig, A.E., Vayenas, D.V., Davidson, C.I. and Pandis, S.N. (2004). Modeling the diurnal variation of nitrate during the Pittsburgh Air Quality Study. J. 
Geophys. Res. 109: D16S06. https://doi.org/10.1029/200 3JD004149

Toon, O.B., Pollack, J.B. and Khare, B.N. (1976). The optical constants of several atmospheric aerosol species: Ammonium sulfate, aluminum oxide, and sodium chloride. J. Geophys. Res. 81: 5733-5748. https://doi.org/10.1029/ JC081i033p05733

Ueda, S., Osada, K. and Takami, A. (2011). Morphological features of soot-containing particles internally mixed with water-soluble materials in continental outflow observed at Cape Hedo, Okinawa, Japan. J. Geophys. Res. 116: D17207. https://doi.org/10.1029/2010JD015565

Ueda, S., Nakayama, T., Taketani, F., Adachi, K., Matsuki, A., Iwamoto, Y. and Matsumi, Y. (2016). Light absorption and morphological properties of soot-containing aerosols observed at an East Asian outflow site, Noto Peninsula, Japan. Atmos. Chem. Phys. 16: 2525-2541. https://doi.org/10.5194/acp-16-2525-2016

Wang, X., Zhang, Y., Chen, H., Yang, X., Chen, J. and Geng, F. (2009). Particulate nitrate formation in a highly polluted urban area: A case study by single-particle mass spectrometry in Shanghai. Environ. Sci. Technol. 43: 3061-3066. https://doi.org/10.1021/es8020155

$\mathrm{Yu}, \mathrm{K} ., \mathrm{Zhu}, \mathrm{O} ., \mathrm{Du}, \mathrm{K}$. and Huang, X.F. (2018). Characterization of nighttime formation of particulate organic nitrates based on high-resolution aerosol mass spectrometry in an urban atmosphere in China. Atmos. Chem. Phys. 19: 5235-5249 https://doi.org/10.5194/acp2018-1009

Zhang, D., Iwasaka, Y., Matsuki, A., Ueno, K. and Matsuzaki, T. (2006). Coarse and accumulation mode particles associated with Asian dust in southwestern Japan. Atmos. Environ. 40: 1205-1215. https://doi.org/10. 1016/j.atmosenv.2005.10.037

Received for review, January 16, 2020

Revised, July 3, 2020

Accepted, July 5, 2020 